\title{
Seasonal changes in ambulatory blood pressure in employees under different indoor temperatures
}

\author{
Estela Kristal-Boneh, Gil Harari, Manfred S Green, Joseph Ribak
}

\begin{abstract}
Objective-The effect of indoor temperature control on summer and winter ambulatory blood pressure levels at work was studied.

Method-Ambulatory systolic blood pressure (SBP) and diastolic blood pressure (DBP) were monitored once in summer and once in winter in 101 healthy normotensive subjects aged 28-63 years, engaged in similar physical work, from two plants with and three without air conditioning. Subjects were interviewed about health related habits, and measurements of environmental and occupational conditions were obtained.

Results-After controlling for possible confounders, mean SBP and DBP during work were significantly higher in winter than in summer $(\Delta \mathrm{SBP}=\mathbf{3 . 4} \mathrm{mm} \mathrm{Hg}, P=$ 0.035; $\triangle$ DBP $=3.3 \mathrm{~mm} \mathrm{Hg}, P<0.003)$. The seasonal change in SBP and DBP showed an independent association with the presence or absence of air conditioning of the industrial plants (SBP: $\beta=$ 0.194, $P<0.0001$; DBP: $\beta=0.054, P=$ $0 \cdot 038)$. The percentage of subjects with increases of more than $10 \mathrm{~mm} \mathrm{Hg}$ from summer to winter was higher in plants without than with air conditioning.
\end{abstract}

Conclusions-(1) In normotensive subjects ambulatory working $B P$ varies by season, with higher values in winter. If validated for hypertensive subjects, it may be necessary to tailor drug treatment to these variations. (2) The findings make it clear that drawing valid conclusions from comparisons of BPs between groups requires controlling for several factors, particularly season of the year. (3) Climatic conditions in the industrial plant influence the magnitude of seasonal variations in BP. Work in plants without air conditioning places a considerable added load on the employee's cardiovascular system.

(Occup Environ Med 1995;52:715-721)

Keywords: indoor temperature; blood pressure; occupational

Owing to the direct association between the risk of cardiovascular disease and blood pressure $(\mathrm{BP}),{ }^{12}$ it has been suggested that the excessive cardiovascular diseases in winter may be partly due to seasonal variations in BP. ${ }^{3-7}$ Laboratory studies show an increase in BP during sudden exposure to $\operatorname{cold}^{8}$ and greater pressor responses to cold in hypertensive people than in normotensive people (more in winter than in summer). ${ }^{9}$ Furthermore, it is well recognised that during exposure to cold the cutaneous vasculature contracts, increasing peripheral resistance, which in turn causes augmented central blood volume and higher blood pressures. ${ }^{1011}$

Casual blood pressure has been found to be higher in winter in both normotensive and hypertensive people. ${ }^{11-19}$ To the best of our knowledge, data on seasonal variations in ambulatory BP are available for only one small sample of hypertensive people ${ }^{20}$ and a small sample of recumbent women ${ }^{21}$; a cross sectional study of different subjects in each season has also been reported. ${ }^{17}$ The association between other risk factors, indoor and outdoor temperatures, seasonal changes in health related habits, occupational conditions, and seasonal changes in ambulatory BPs has not been described.

Assuming that ambient temperature is among the causes of BP being higher in winter than in summer and that acute exposure to cold or heat affects BP, it can be hypothesised that employees who work for the greater part of the day in a closed, air conditioned environment are less exposed to the acute seasonal variations caused by ambient temperature. Plant conditions, therefore, are likely to have an effect on the stability of BP. In the light of the health risk that may result from working in an unsuitable environment, we decided to examine the extent to which the stability of BPs of workers in different seasons of the year is affected by different plant conditions. To evaluate this issue we monitored ambulatory systolic BP (SBP) and diastolic BP (DBP) and performed casual BP measurements during summer and winter months in 101 healthy normotensive employees aged 28-63 years; environmental temperatures (indoor and outdoor), health related habits, and occupational conditions were determined as well.

\section{Methods}

STUDY POPULATION

The target population comprised 154 male employees working in the machining departments (fitting and turning) of five different plants, two of which were air conditioned and three of which were not. In the air conditioned buildings a temperature control system was used for both heating and cooling. The distance between the plants did not exceed $50 \mathrm{~km}$. Every employee was offered the 
examination free of charge. At the beginning of the study all subjects were informed about the risks and discomfort involved in participation in the project. It was explained that they were being asked to volunteer for research purposes only and that their sole compensation would be the receipt of the results of the medical tests carried out during the study. The study was approved by the local Research on Human Subjects Committee. All participants signed an informed consent form, and they were able to withdraw from the study at any time they wished. The response rate was $95 \%$. During the study days the volunteers were asked not to change their regular way of life.

\section{NATURE OF THE WORK}

Machining departments were selected to eliminate departmental differences caused by the nature of the work. Machining departments can be found in plants both with and without air conditioning. Employees are required to have at least an 11th grade education (a satisfactory level for filling out questionnaires). The only difference between the plants was the type and nature of the products produced: mostly machine parts, and less frequently, finished products.

\section{CLASSIFICATION OF PLANTS BY TEMPERATURE} CONTROL

An air conditioned plant was defined as one in which the temperature on the production floors remained constant for the entire working day, either by means of a central air conditioning system or by split or window air conditioning units. A plant without air conditioning was defined as one in which there was neither a central air conditioning system nor separate air conditioning units, so that the temperature on the production floors was affected by the outside environmental temperature. Plants in which fans were used were considered to be not air conditioned.

\section{Description of central air conditioning}

A central air conditioning system is an automatic system located in a machine room and connected to the production floors by ducts that transport warm or cold air as required. A central air conditioning system can be controlled only by a central thermostat and not by the individual worker. An air conditioned building has a roof and is enclosed.

Exposure to additional environmental hazards During the production process the workers are exposed to the noise of the machines. In each plant the noise level was measured by a Quest M-27 device. The noise level measured equalled an eight hour shift (LEQ) and was on average $84.2 \mathrm{~dB}(\mathrm{~A})$ with no significant differences between the plants. The maximum (non-continuous) noise was also measured; the average was $115 \cdot 1 \mathrm{~dB}(\mathrm{~A})$ with no significant difference between the plants.

\section{STUDY DESIGN}

The study was cross sectional in design and carried out on site, on regular working days, in two identical stages (summer and winter). In two plants the first stage was carried out in winter and in the other plants in summer to ensure that the results would not be affected by the order of the tests. In both stages the tests were conducted at the same time of day.

Two to three subjects were examined and monitored each day, until this substage was completed. Each subject completed the questionnaire at the end of the day on which he was monitored.

\section{EXAMINATIONS}

The field tests included an examination of the environmental conditions in the workplace and physiological tests.

\section{Examination of the environmental conditions in the workplace}

A meteorological system (Model M-1/B, YM Electronic Industries, Tel Aviv) containing sensors and a data logger to detect and record the relative humidity, dry temperature, heat radiation, and wind velocity was set up as close as possible to the worker. The system was set up before the employee arrived at work and was operated continuously until the end of the working day.

\section{Sensor specifications}

The hygrometer is accurate to $0 \cdot 1 \%$, with a $0.5 \%$ error of measurement (C-83 Solid State Capacitive, Rotronic, Zurich, Switzerland). Sensors for the surrounding dry temperature and the globe are accurate to $0 \cdot 1{ }^{\circ} \mathrm{C}$, with a $0.1^{\circ} \mathrm{C}$ error of measurement (I-128 $\mathrm{Pt} 100$ RTD, Rotronic, Zurich, Switzerland). The anemometer (model 30 ) is accurate to 0.05 miles/hour, with a range of $0-100$ and a $0 \cdot 15$ error of measurement. Also, hourly information about the environmental temperature and the relative humidity outside the plants during the day was obtained from the meteorological services at Beit Dagan and at the Ben-Gurion airport.

\section{Physical examinations}

Each worker was examined between 600 and $900 \mathrm{am}$, before the beginning of the working day in a temperature controlled room in the presence of a technician only.

- The seated subject remained in repose for five minutes while the technician filled out the test form.

- Three BP measurements were made with a mercury manometer (sphygmomanometer), accurate to $2 \mathrm{~mm} \mathrm{Hg}$, while the subject was seated, with one-minute intervals between measurements. Pulse was measured while the subject was seated.

- Height and weight were measured, without shoes, and with the subject wearing only light industrial clothing.

- The subject was fitted with portable devices for measuring heart rate (HR) and BP.

- The subject was given an explanation about how information and environmental data should be recorded in the daily activity journal (used to evaluate the extent of the load 
and the other conditions to which the subject was exposed during each measurement).

- The devices were checked to ensure that they were in working order and that they had been properly installed by simultaneously measuring BP with the ambulatory $\mathrm{BP}$ device and the mercury manometer (sphygmomanometer). Two simultaneous measurements were carried out at one-minute intervals while the subject was seated.

- The subject was given an oral thermometer with which he was instructed to take his temperature every four hours. He then left to begin a normal working day.

- On the following morning after measurements had been recorded for 24 hours the subject returned the equipment.

Examinations were always done at the same time of the day. Ambulatory HR and BP were monitored by the Accutracker II, Stech, USA Medical Instruments, Raleigh, NC. The device for monitoring ambulatory BP underwent evaluation tests, and satisfactory results were obtained. ${ }^{22}$ It weighed only $300 \mathrm{~g}$ and therefore was not uncomfortable for the subject to wear on his body. It was programmed to measure BP every 15 minutes. The subjects were asked to lower their arms and remain inactive during the test. The records were revised to eliminate all measurements that the device had detected as abnormal. Those

Figure 1 Daily body temperature in $(A)$ plants without air conditioning and $(B)$ air conditioned plants.

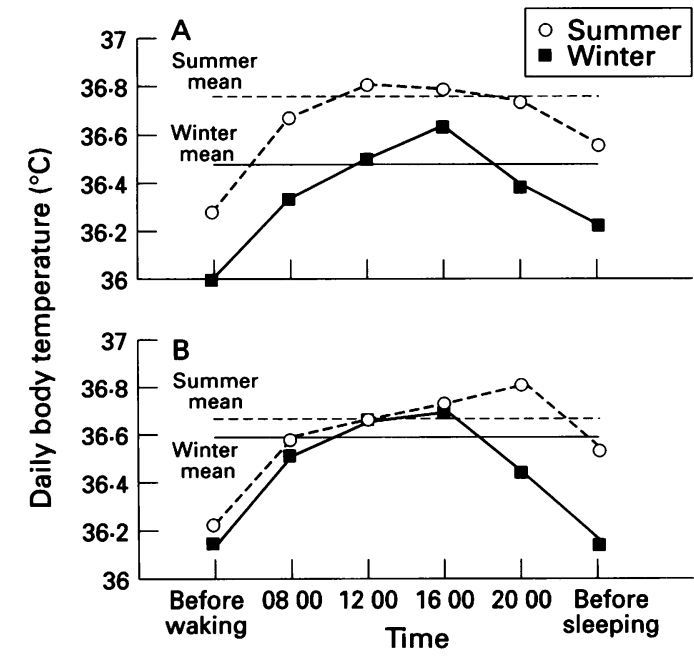

Table 1 Characteristics of the study population (summer data)

\begin{tabular}{llll}
\hline & Air conditioning & No air conditioning & P value \\
\hline Sample size & 46 & 66 & \\
Mean (SD, range) age (y) & $46 \cdot 5(8 \cdot 6,26-64)$ & $43 \cdot 9(9 \cdot 2,28-65)$ & NS \\
Mean (SD, range) height (cm) & $170 \cdot 0(6 \cdot 3,159-185)$ & $170 \cdot 8(6 \cdot 9,150-185)$ & NS \\
Ethnic origin (\%): & & & $0 \cdot 023$ \\
Jews by origin: & $17 \cdot 1$ & $19 \cdot 7$ & \\
$\quad$ Northern Africa & $24 \cdot 3$ & $12 \cdot 7$ & \\
Asia & $42 \cdot 9$ & $52 \cdot 1$ & \\
Western Europe & $15 \cdot 7$ & $9 \cdot 9$ & NS \\
Yemen & - & $5 \cdot 6$ & NS \\
Arabs & $33 \cdot 3$ & $36 \cdot 9$ & $0 \cdot 004$ \\
Physically active at home & 47 & 55 & $\mathrm{NS}$ \\
(\% once/week) & 14 & 36 & \\
Alcohol consumption (\%) & $\mathbf{8 4}$ & 93 & \\
Cigarette smoking (\%) & & & \\
Coffee drinking (\%) & &
\end{tabular}

^By father's country of birth (or paternal grandfather if father was born in Israel). records in which at least $80 \%$ of the possible readings were standard were included in the research. Averages were calculated for all the readings in each hour of work time.

Body weight was measured with the Seca electronic scale, accurate to $100 \mathrm{~g}$.

Internal body temperature was measured with an oral digital thermometer manufactured by Amron Company and accurate to $0.01^{\circ} \mathrm{C}$. We anticipated that this would be the only operational method to which the subjects would not object. According to the findings of Strydom et al, ${ }^{23}$ based on their hundreds of measurements oral temperature is lower than rectal temperature by about $0 \cdot 7^{\circ} \mathrm{C}$. This difference is not affected by surrounding conditions or the pace of work; it remains constant over a broad range of temperatures and does not vary at higher limits, as might be expected.

\section{QUESTIONNAIRES}

Questionnaires were used to gather demographic data and data about health habits such as smoking (cigarettes a day), coffee consumption (cups a day), alcohol consumption ( $\mathrm{ml}$ a month), involvement in sports activities (hours a week), and general state of health, family disease history, nutritional habits, environmental problems, somatic complaints, etc. The subjects filled out the same questionnaires twice, once in winter and once in summer. It was emphasised that they were to refer to the month during which the test was being given and not to give general answers.

\section{EXCLUSIONS}

At the beginning of the study a total of 146 employees were examined. Those tested in one season only $(n=7)$, those with less than 22 hours of ambulatory monitoring $(n=25)$, night shift workers $(n=1)$, and women $(n=$ 1) were eliminated from the sample. Complete data were available for 112 subjects; of these 11 were receiving treatment for hypertension or for cardiovascular disease and were included only in those analyses in which the use of medication was inconsequential.

\section{STATISTICAL ANALYSIS}

The following data analyses were carried out with the SAS software (SAS Institute, Cary, NC, USA) ${ }^{24}: t$ test to examine the differences between the two research groups (plants with and without air conditioning) for the quantitative variables, and $\chi^{2}$ and Fisher exact test for differences in categorical variables (table 1); paired $t$ test or Sign rank test (non-parametric) to examine seasonal variations among the subjects for the quantitative variables with and without normal distribution among subjects, respectively; and $t$ test to examine the differences between research groups (tables 2 and 3, and fig 1); analysis of covariance with repeated measurements was used to examine the variations in ambulatory BP and the association between season and indoor temperature on the entire population, with control for potential confounding variables (see results, not tables). 
Table 2 Environmental conditions during the study days

\begin{tabular}{|c|c|c|c|c|c|c|}
\hline & \multicolumn{3}{|l|}{ Air conditioning } & \multicolumn{3}{|l|}{ No air conditioning } \\
\hline & Summer & Winter & Pvalue & Summer & Winter & Pvalue \\
\hline $\begin{array}{l}\text { Outdoor daily temperature }\left({ }^{\circ} \mathrm{C}\right) \\
\text { Outdoor daily humidity }(\%) \\
\text { Outdoor temperature during work }\left({ }^{\circ} \mathrm{C}\right) \\
\text { Discomfort index } \\
\text { Outdoor humidity during work }(\%) \\
\text { Mean dry indoor temperature at work }\left({ }^{\circ} \mathrm{C}\right) \\
\text { Mean radiant indoor temperature at work }\left({ }^{\circ} \mathrm{C}\right) \\
\text { Mean indoor relative humidity at work }(\%) \\
\text { Mean indoor air velocity at work }(\mathrm{m} / \mathrm{s})\end{array}$ & $\begin{array}{l}28 \cdot 3(1 \cdot 1) \\
68(33) \\
28 \cdot 3(1 \cdot 1) \\
\text { Medium } \\
64(30) \\
25 \cdot 0(2 \cdot 2) \\
25 \cdot 5(2 \cdot 1) \\
60 \cdot 5(6 \cdot 8) \\
0 \cdot 01(0 \cdot 03)\end{array}$ & $\begin{array}{l}14 \cdot 5(3 \cdot 4) \\
59(13) \\
14 \cdot 6(3 \cdot 4) \\
\overline{56}(14) \\
22 \cdot 1(1 \cdot 7) \\
22 \cdot 6(1 \cdot 7) \\
40 \cdot 6(9 \cdot 6) \\
0 \cdot 00(0 \cdot 00)\end{array}$ & $\begin{array}{l}<0.0001 \\
\text { NS } \\
<0.0001 \\
\text { NS } \\
<0.0001 \\
<0.0001 \\
<0.0001 \\
\text { NS }\end{array}$ & $\begin{array}{l}28 \cdot 7(1 \cdot 0) \\
64(5 \cdot 4) \\
28 \cdot 7(1 \cdot 0) \\
\text { Medium } \\
60(5 \cdot 8) \\
29 \cdot 1(1 \cdot 4)^{\star \star \star} \\
29 \cdot 7(1 \cdot 2)^{\star \star \star} \\
69 \cdot 3(6 \cdot 5)^{\star \star \star} \\
0 \cdot 10(0 \cdot 20)^{\star \star \star}\end{array}$ & $\begin{array}{l}12 \cdot 1(3 \cdot 1)^{\star \star \star} \\
68(13)^{\star \star \star} \\
12 \cdot 1(3 \cdot 1)^{\star \star \star} \\
\frac{1}{65}(14)^{\star \star \star} \\
15 \cdot 7(3 \cdot 3)^{\star \star \star} \\
17 \cdot 0(3 \cdot 2)^{\star \star \star} \\
58 \cdot 3(12 \cdot 0)^{\star \star \star} \\
0 \cdot 02(0 \cdot 06)^{\star \star \star}\end{array}$ & $\begin{aligned}< & 0.000 \\
& 0.025 \\
< & 0.000 \\
& \\
& 0.011 \\
< & 0.000 \\
< & 0.000 \\
< & 0.000 \\
& 0.002\end{aligned}$ \\
\hline
\end{tabular}

$\star \star \star P<0.001 v$ air conditioning.

Table 3 Summer and winter values of health related habits related to BP (mean (SD))

\begin{tabular}{|c|c|c|c|c|c|c|}
\hline & \multicolumn{3}{|c|}{ Air conditioning } & \multicolumn{3}{|c|}{ No air conditioning } \\
\hline & Summer & Winter & Pvalue & Summer & Winter & P value \\
\hline $\begin{array}{l}\text { Weight (kg) } \\
\text { Water drinking (cups/day) } \\
\text { Coffee consumption (cups/day) } \\
\text { Tea consumption (cups/day) } \\
\text { Cigarette smoking (n/day) } \\
\text { Alcohol consumption (ml/month) }\end{array}$ & $\begin{array}{l}75 \cdot 5(13 \cdot 2) \\
5 \cdot 7(2 \cdot 3) \\
2 \cdot 2(1 \cdot 7) \\
1 \cdot 5(1 \cdot 6) \\
12 \cdot 5(8 \cdot 3) \\
94(186)\end{array}$ & $\begin{array}{c}76 \cdot 8(13.4) \\
4.9(3.4) \\
2 \cdot 8(1.8) \\
1.3(1.5) \\
16 \cdot 2(7.9) \\
119(180)\end{array}$ & $\begin{array}{l}0.001 \\
0.084 \\
0.001 \\
\text { NS } \\
0.081 \\
\text { NS }\end{array}$ & $\begin{array}{l}77 \cdot 2(13 \cdot 2) \\
8 \cdot 3(3 \cdot 9)^{\star \star \star} \\
2 \cdot 8(1 \cdot 5) \\
1 \cdot 0(1 \cdot 4) \\
21 \cdot 7(9 \cdot 6)^{\star \star \star} \\
130(224)\end{array}$ & $\begin{array}{c}78 \cdot 3(13 \cdot 7) \\
4 \cdot 2(3 \cdot 5) \\
2 \cdot 7(1 \cdot 5) \\
1 \cdot 7(1 \cdot 5) \\
21 \cdot 6(8 \cdot 8) \\
131(260)\end{array}$ & $\begin{array}{l}\quad 0.036 \\
<0.0001 \\
\text { NS } \\
\text { NS } \\
\text { NS } \\
\text { NS }\end{array}$ \\
\hline
\end{tabular}

$\star \star \star P<0.001$ air conditioning $v$ no air conditioning.

Table 4 Regression coefficients for the change in BP (winter to summer) at work

\begin{tabular}{lclllll}
\hline & \multicolumn{3}{l}{$\Delta S B P$} & & \multicolumn{1}{l}{$\Delta D B P$} & \\
\cline { 2 - 3 } Independent variables & Standardised $\beta$ & P value & & Standardised $\beta$ & P value \\
\hline Air conditioning (yes, no) & 0.194 & $<0.0001$ & & 0.054 & 0.038 \\
Age (y) & 0.035 & NS & & -0.014 & NS \\
$\Delta$ Cigarette smoking (n/day) & -0.053 & 0.029 & & -0.047 & 0.056 \\
$\Delta$ Weight (kg) & 0.049 & NS & & 0.070 & 0.046 \\
Sport (yes, no) & -0.121 & $<0.0001$ & & 0.053 & NS \\
\hline
\end{tabular}

Potential confounders that were found not significant were not included in the analysis of variance with repeated measurements. Adjustment for potential confounding variables was applied to compare the study groups in quantitative variables and analyse the winter to summer differences in $\mathrm{BP}$ and HR (tables 4 and 5).

Statistical significance refers to a $5 \%$ level.

\section{Results}

Table 1 shows the characteristics of the study population. There were small but significant differences in the percentage of smokers between the two kinds of industrial plants. This variable was controlled for in the statistical analyses.

ENVIRONMENTAL CONDITIONS

Table 2 shows the climatic environmental conditions to which the subjects were exposed on the days of the study. As anticipated, summer temperatures were significantly higher than winter temperatures. There were also significant differences in climatic conditions between plants with and without air conditioning $(P<0.0001)$.

\section{BODY TEMPERATURE}

Figure 1 shows the mean body temperatures of the subjects in summer and winter by pres- ence or absence of air conditioning. For the entire population, the mean (SD) daily temperature was higher in summer than in winter $\left(36.7(0.3)^{\circ} \mathrm{C} v 36.5(0.3)^{\circ} \mathrm{C}, \mathrm{P}<0.0001\right)$. When the population was divided according to presence or absence of air conditioning in the plant, the difference in mean body temperature between summer and winter was significant only among the subjects in the plants without air conditioning (summer to winter difference in air conditioned plants $=0.1^{\circ} \mathrm{C}$, $P=0.2242$; summer to winter difference in plants without air conditioning $=0.3^{\circ} \mathrm{C}$, $\mathrm{P}<0.0001$ ).

\section{CORRELATES OF HEALTH RELATED HABITS}

AND BP

Table 3 shows the means of health related habits in summer and winter. Only employees in the plants without air conditioning drank more water in summer than in winter. Mean body weight was higher in winter than in summer.

SEASONAL CHANGES IN BP

Comparisons of the data, controlling for age, ethnic origin, body mass index, coffee, alcohol, cigarette consumption, and participation in sport indicated that for the entire population mean SBP and DBP at work were significantly higher in winter than in summer $(130.7$ $v 127.7 \mathrm{~mm} \mathrm{Hg}, \mathrm{P}<0.03$; and 78.1 v 74.8 $\mathrm{mm} \mathrm{Hg}, \mathrm{P}<0.003$, respectively). In analyses of covariance BP showed an independent association with season and with indoor environmental temperature (SBP: $\beta=3.98 \mathrm{~mm}$ $\mathrm{Hg}$ and $-1.14 \mathrm{~mm} \mathrm{Hg} /{ }^{\circ} \mathrm{C}$, respectively; DBP: $\beta=4.39 \mathrm{~mm} \mathrm{Hg}$ and $-0.58 \mathrm{~mm}$ $\mathrm{Hg} /{ }^{\circ} \mathrm{C}$ respectively).

ASSOCIATION BETWEEN SEASON AND CONTROL OF INDOOR TEMPERATURE WITH BP AT WORK

Table 4 shows the association between personal and environmental factors and the sea- 
Table 5 Working means ${ }^{*}$ and $\triangle$ (winter to summer) of $B P, H R$, and the double product $S B P \times H R$ with and without air conditioning in the plant

\begin{tabular}{|c|c|c|c|c|c|c|c|c|}
\hline & \multicolumn{4}{|c|}{ Air conditioning } & \multicolumn{4}{|c|}{ No air conditioning } \\
\hline & Summer & Winter & $\Delta(95 \% C I)$ & $P$ value & Summer & Winter & $\Delta(95 \% C I)$ & Pvalue \\
\hline $\begin{array}{l}\text { Mean SBP at work }(\mathrm{mm} \mathrm{Hg}) \\
\text { Mean DBP at work }(\mathrm{mm} \mathrm{Hg}) \\
\text { Mean HR at work }(\mathrm{bpm}) \\
\text { SBP } \times \text { HR at work }(\mathrm{mm} \mathrm{Hg} \cdot \mathrm{bpm})\end{array}$ & $\begin{array}{r}129 \cdot 4 \\
75 \cdot 8 \\
75 \cdot 6 \\
97 \cdot 6\end{array}$ & $\begin{array}{r}130 \cdot 9 \\
79 \cdot 4 \\
78 \cdot 7 \\
102 \cdot 8\end{array}$ & $\begin{array}{l}1.17(0.34 \text { to } 1.99) \\
3.38(2.80 \text { to } 3.96) \\
3.03(2.29 \text { to } 3.75) \\
4.97(3.78 \text { to } 6.16)\end{array}$ & $\begin{array}{l}0.005 \\
<0.0001 \\
0.002 \\
<0.0001\end{array}$ & $\begin{array}{r}128 \cdot 2 \\
74 \cdot 1 \\
82 \cdot 6 \\
106 \cdot 1\end{array}$ & $\begin{array}{r}132 \cdot 2 \\
77 \cdot 3 \\
82 \cdot 6 \\
109 \cdot 6\end{array}$ & $\begin{array}{c}4.30(3.54 \text { to } 5.05) \\
3.22(2.71 \text { to } 3.73) \\
-0.04(-0.7 \text { to } 0.64) \\
3.46(2.34 \text { to } 4.58)\end{array}$ & $\begin{array}{l}<0.0001 \\
<0.0001 \\
\text { NS } \\
<0.0001\end{array}$ \\
\hline
\end{tabular}

*Values adjusted for age, weight, cigarette consumption, and sport.

Figure 2 Winter to summer differences in blood pressure at work by air conditioning of the plant.

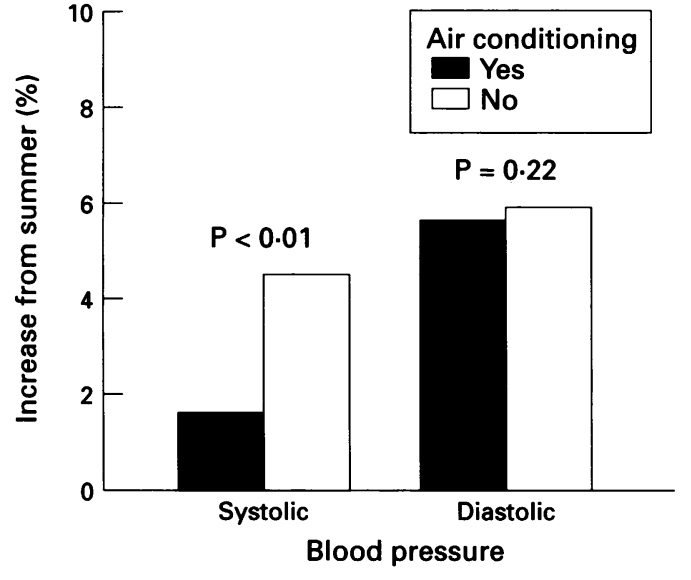

sonal change in BP at work. It was found that the increase in BP from summer to winter was higher among subjects in plants without air conditioning than those in plants with. Table 5 shows means values and differences of SBP, $\mathrm{DBP}, \mathrm{HR}$, and the double product $\mathrm{SBP} \times \mathrm{HR}$ between winter and summer by presence or absence of air conditioning at the plant. There were no differences in the mean nocturnal BP values between kinds of plants (data not shown). Figure 2 shows the winter to summer differences in BP at work (as a percentage of summer values) by presence or absence of air conditioning at the plant. Figure 3 shows the distribution of subjects by categories of increase of BP in winter at work by air conditioning.

The SBP at work was seasonally more stable in the air conditioned plants. The percentage of subjects with increases in BP of more than $10 \mathrm{~mm} \mathrm{Hg}$ was higher in the plants without than with air conditioning.

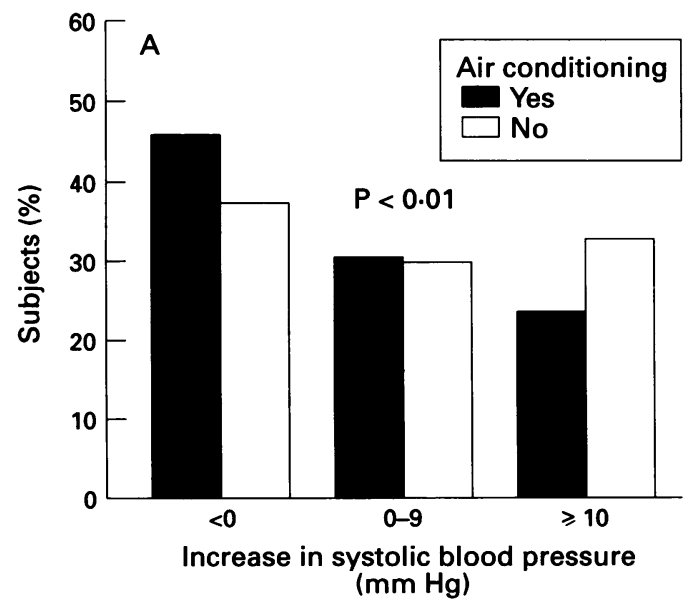

Figure 3 Distribution of subjects by amount of increase of blood pressure in winter at work. ( $\mathrm{mm} \mathrm{Hg}$ )

\section{Discussion}

We studied the effect of indoor temperature control-a possible factor for interventionon BP levels at work in the summer and winter. Outdoor and indoor climatic conditions were examined, and we included subjects who worked in plants with and without air conditioning. In this way, it was possible to distinguish between the variations in BPs that affect the entire population and result from seasonal rhythms, which are not dependent on work conditions, and the variations that result solely from climatic conditions in the plant. Also, it was decided to limit, as much as possible, any differences due to additional exposure and physical exertion at work to compare populations that differ chiefly in their exposure to climatic conditions in the workplace. It is important to note that tests were not carried out under "Sharav" heat wave (similar to Santa Anna winds) conditions or on days of extreme cold. Thus, the climatic conditions examined in our work represent the general range of temperatures to which the Israeli worker is exposed during any normal season, and not extremes of heat or cold.

EVIDENCE OF PHYSIOLOGICAL VARIATIONS DUE TO DIFFERENCES IN EXPOSURE TO CLIMATIC CONDITIONS BETWEEN INDUSTRIAL PLANTS A comparison of the climatic conditions inside the plants shows that there were clear differences in both winter and summer. In summer the plants without air conditioning were hot and the air conditioned plants were more comfortable, whereas in winter the plants without air conditioning were cold and the air conditioned plants were again more comfortable. Thus, in both seasons, the tem-

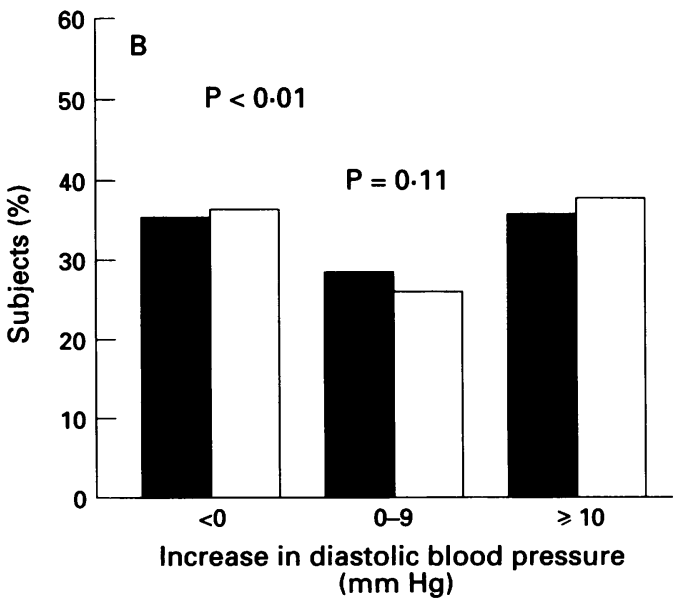


peratures in the air conditioned plants were within the range considered comfortable for the working person (thermoneutral) ${ }^{25}$; whereas in the plants without air conditioning the temperatures were outside this range. These differences in exposure between workers in the two types of plants were also expressed by differences in internal body temperature (fig 1). No significant seasonal differences in body temperature during working hours were found for the workers in the air conditioned plants, although there were significant differences among the workers in the plants without air conditioning. In winter, during working hours, the body temperature of the workers in the air conditioned plants was higher than that of the workers in the plants without air conditioning. Thus, it can be assumed that in winter workers in the air conditioned plants needed to use fewer resources to heat their bodies. In summer, during working hours the body temperature of the workers in the plants without air conditioning was higher; again, it can be assumed that these workers had to use more resources to dissipate body heat. This was shown by, among other things, a relatively higher consumption of liquids by the workers in the plants without air conditioning in the summer.

EFFECT OF CLIMATIC CONDITIONS ON SEASONAL STABILITY OF BP DURING WORKING HOURS

Entire population

It was found that the average SBP at work was significantly higher in winter than in summer. This finding agrees with the studies already mentioned that indicate that for the most part $\mathrm{BP}$ measured in the clinic (in the morning) is higher in winter than in summer. ${ }^{11-19}$

Thermal regulation may explain the greater increase in BP during work time in winter than in summer. A considerable amount of cardiac output is channelled to the peripheral circulation in summer to ensure heat dissipation from the body, whereas much less is channelled in winter to prevent heat loss. In other words, a given increase in HR will cause a greater increase in BP in winter than in summer

\section{Air conditioning}

In the first section of this discussion we dealt with the differences in the workers' exposure to climatic conditions between plants with and without air conditioning and how these differences affect body temperature. In the air conditioned plants the ambient temperature remains stable in the thermoneutral range in both seasons, whereas the plants without air conditioning are cold in winter and hot in summer. After controlling for many confounding factors, it was found that during working hours, HRs and the double product SBP $\times$ HR were higher for employees in the plants without air conditioning than for employees doing the same work in the air conditioned plants (table 5). In both seasons the HR of employees in the plants without air conditioning was higher than that of their counterparts in the air conditioned plants. As these findings were obtained after controlling for known variables that affect HR (smoking, age, sports activities) and the selection of plants made the physical work carried out very similar, it seems that there is a causal relation between temperature control in industrial plants and the HR of workers in those plants.

In both seasons, the increase in HR may express the need for increased cardiac output; in the winter, due to increased metabolic requirements; in the summer, due to the need to channel greater blood volume to the peripheral circulation for cooling purposes. Thus, it seems that work in plants without air conditioning places an added load on the employee's cardiovascular system, both in winter and in summer. Climatic conditions in the plant also have a considerable effect on BP. Figure 2 shows that the differences in BP between summer and winter are greater for workers in plants without air conditioning; the reason for this correlates with the findings for HR; in the winter, the thermal stimulus is greater for workers in plants without air conditioning and, therefore, cardiac output and BP are higher than for workers in air conditioned plants; in the summer, workers in plants without air conditioning must allot more resources for cooling purposes, and more blood is channelled to the peripheral circulation, thereby decreasing BP and increasing HR. These findings should not lead to the conclusion that it is healthier to work in a plant without air conditioning in the summer, as in the final analysis the load on the cardiovascular and thermoregulatory systems and on the heart is greater in those plants.

It must be remembered that only healthy subjects were included in the present study and what has been described are healthy physiological responses. The question that must now be asked is: what are the implications of these findings for hypertensive workers, for those who have inefficient thermal regulation, and for those who perform more strenuous types of task? Naturally, the question of how climate affects those who work out of doors (completely exposed to climatic conditions) and those who work under conditions of extreme heat and cold must also be investigated.

\section{Conclusions}

In normotensive people ambulatory working BP varies by season, with higher values in winter. If validated for hypertensive people, it may be necessary to tailor drug treatment to these variations. The findings make it clear that drawing valid conclusions from comparisons of BPs between groups requires controlling for several factors, particularly season of the year. Climatic conditions in the industrial plant influence the magnitude of seasonal variations in BP. Work in plants without air conditioning places a considerable added load on the employee's cardiovascular system. If 
increased BP is a causal factor in increased cardiovascular morbidity in winter, then workers in plants without air conditioning may have a higher risk of cardiovascular morbidity in winter than workers in similar work but in heated plants.

This study was supported by the Committee for Preventive Action and Research in Occupational Health, Ministry of Labor and Social Affairs, Jerusalem, Israel.

1 Holme I, Helgeland A, Hjermann I, Leren P, Lund-Larsen PG. Four and two-thirds years incidence of coronary heart disease in middle-aged men: the Oslo study. $A m$ f Epidemiol 1980;112:149-60.

2 Kannel WB. Status of risk factors and their consideration in antihypertensive therapy. $A m \mathcal{F}$ Cardiol 1987;59: $80 \mathrm{~A}-90 \mathrm{~A}$.

3 Alderson MR. Season and mortality. Health Trends 1985; 17:87-96.

4 Abdulla K, Taka M. Climatic effects on blood pressure in normotensive and hypertensive subjects. Postgrad Med $\mathcal{F}$ 1988;64:23-6.

5 Curwen M. Trends in respiratory mortality 1951-75, England and Wales. London: HMSO. (OPCS DH1No 7.)

6 Epstein SE, Stampfer M, Beiser GD, Goldstein RE Braunwald $\mathrm{E}$. Effects of a reduction in environmental temperature on the circulatory response to exercise in man. Implications concerning angina pectoris. $N$ Engl f Med 1969;280:7-11.

7 Green MS, Harari G, Kristal-Boneh E. Excess winter mortality from ischemic heart disease and stroke during colder and warmer years in Israel: an evaluation and colder and warmer years in Israel: an evaluation and European fournal of Public Health 1994;4:3-11.

8 Keatinge WR, McCance RA. Increase in venous and arterial pressure during sudden exposure to cold. Lancet 1957;270:208.

9 Tanaka S, Konno A, Hashimoto A, Hayase A, Takagi Y, Kondo $S$, et al. The influence of cold temperatures on the progression of hypertension: an epidemiological study. F Hypertens 1989;7(suppl 1):S49-51.

10 Raven PB, Niki I, Dahms TE, Horvath SM. Compensatory cardiovascular responses during an environmental cold stress, $5^{\circ} \mathrm{C}$. $₹$ Appl Physiol 1970;29:417-21.

11 Raven PB, Wilkerson JE, Horvath SM, Boulduan NW. Thermal, metabolic and cardiovascular responses to var- ious degrees of cold stress. Can 7 Physiol Pharmacol 1975;53:293-8.

12 Rose G. Seasonal variation in blood pressure in man. Nature 1961;189:235.

13 Brennan PJ, Greenberg G, Miall WE, Thompson SG Seasonal variation in arterial blood pressure. $B M F 1982$ 285:919-23.

14 Heller RF, Rose G, Tungstall-Pedoe HD, Christie DGS. Blood pressure measurement in the United Kingdom heart disease prevention project. $\mathcal{F}$ Epidemiol Community Health 1978;32:235-8.

15 Hata T, Ogihara T, Maruyama A, Mikami H, Nakamani $M$, Naka $T$, et al. The seasonal variation of blood pres$\mathrm{M}$, Naka $\mathrm{T}$, et al. The seasonal variation of blood pressure in patients with essential

16 Nayha Simo. Adjustment of blood pressure data by season. Scand F Prim Health Care 1985;3:99-105.

17 Green MS, Schwartz K, Harari G, Najenson T Association of ambulatory blood pressure and heart rate with ambient temperature. fournal of Ambulatory Monitoring 1991;4:253-60.

18 Keatinge WR, Coleshaw SRK, Cotter F, Mattock M Murphy $M$, Chelliah $R$. Increases in platelet and red cel counts, blood viscosity, and arterial pressure during mild surface cooling: factors in mortality from coronary and surfe cooling. factor in mortalify from coronary and

19 Sharma BK, Sagar S, Sood GK, Varma S, Kalre OP Seasonal variation of arterial blood pressure in normotensives and essential hypertensives. Indian Heart $\mathcal{f}$ 1990;42:66-73.

20 Giaconi S, Palombo C, Genovesi-Ebert A, Marabotti C, Volterrani D, Ghione $S$. Long-term reproducibility and evaluation of seasonal influences on blood pressure monitoring. F Hypertens 1988;6(suppl 4):S64-6.

21 Halberg F, Cornelissen G, Sothern RB, Wallach LA Halberg E, Ahlgren A, et al. International geographic studies of oncological interest on chronobiological variables. In: Kaiser H: ed. Neoplasms. Comparative pathology of growth in animals, plants and man. Baltimore: Williams and Wilkins, 1981:553-96.

22 White WB, Lund-Johansen P, Omvik P. Assessment of four ambulatory blood pressure monitors and measurements by clinicians versus intraarterial blood pressure at ments by clinicians versus intraarterial blood pressure

23 Strydom NB, Morrison JF, Booyens J, Peter J. Comparison of oral and rectal temperatures during work in heat. son of oral and rectal temperat
$\mathcal{f}$ Appl Physiol 1956;8:406-8.

24 SÁS Institute. SAS Language, version 6, 1st ed. Carry, NC SAS Institute, 1989:1042.

25 Foo SC, Phoon WO. The thermal comfort of sedentary workers. Asia and Pacific fournal of Public Health, 1987, 1:74-7.

26 Grivel F, Candas V. Ambient temperatures preferred by young European males and females at rest. Ergonomics 1991;34:365-78.

\section{Correspondence and editorials}

Occupational and Environmental Medicine welcomes correspondence relating to any of the material appearing in the journal. Results from preliminary or small scale studies may also be published in the correspondence column if this seems appropriate. Letters should be not more than 500 words in length and contain a minimum of references. Tables and figures should be kept to an absolute minimum. Letters are accepted on the understanding that they may be subject to editorial revision and shortening.

The journal also publishes editorials which are normally specially commissioned. The Editor welcomes suggestions regarding suitable topics; those wishing to submit an editorial, however, should do so only after discussion with the Editor. 